\title{
Selective attention and the control of binocular rivalry
}

\author{
LEON C. LACK \\ The Flinders University of South Australia, Bedford Park, South Australia 5042
}

\begin{abstract}
The control of binocular rivalry (BR) was reintroduced as an example of selective attention after several decades. Ss passively observed BR in a stereoscopic tachistoscope and, at an undetermined phase of rivalry, received an instruction signal to attend to one of the rivalry patterns. Letter test stimuli were presented to either the instructed (I) eye or noninstructed (NI) eye 1, 3, 5, or $7 \mathrm{sec}$ following the instruction signal. The difference between the eyes in recognition performance (I-NI) provided an objective measure of control, which was correlated with previously used measures based on subjective reports of rivalry alternation rates. Subjective and objective measures showed correlated increases as a result of practice of control. The fact that the objective measure reached a peak value at the 3 -sec delay of test stimuli suggested a minimum time to shift attention and maximum time to maintain attention in BR. In addition, it was found that the control of BR results in a change of signal strength with no associated change in the use of confidence ratings, a result similar to that found with selective attention in dichotic listening.
\end{abstract}

When the eyes receive dissimilar inputs, the observer perceives a phenomenal suppression which alternates between the inputs and which is known as binocular rivalry (BR). Early in the history of psychology, BR was used as an example of the process of attention (Helmholtz, 1925; James, 1891; McDougall, 1903). Indeed, Helmholtz (1873) wrote about rivalry that "there is scarcely any phenomenon so well fitted for the study of the causes which are capable of determining the attention [p. 295]," and Pillsbury (1908), referring to $B R$, stated that "one of the most satisfactory ways of studying many of the phenomena of the attention is by means of a simple stereoscope [p. 32]."

Following a considerable period during which little interest was shown in BR and during which the concept of attention was hardly discussed, there has been a resurgence of interest and experimentation in attention, particularly selective attention with dichotic auditory inputs (Treisman, 1969; Moray, 1969; Swets \& Kristofferson, 1970). Two of these investigators (Treisman, 1969; Moray, 1969) have mentioned BR but have not considered it to be an example of selective attention, on the assumption that it was not susceptible to voluntary control.

However, the evidence from other recent investigations would support the carly psychologists' interest in BR as an example of attention. Meredith and Meredith (1962) found that Ss could accelerate or retard the rate of rivalry alternation, resulting in an average accelerated rate 2.5 times greater than the retarded rate. They attributed this result to "instructional conditions" and considered several peripheral mechanisms such as eye movements, blinking, and muscular tension as possible mechanisms of control. Control of rivalry in unpracticed Ss has been recently reconfirmed, but it has also been found that the extent of control can be increased considerably with practice (Lack, 1969, 1970). With only 10 practice sessions using knowledge of results, Ss produced an average rapid rate/slow rate ratio of 11.3 (Lack, 1970). In addition, it has been found that control of alternation rate does not depend on peripheral mechanisms but rather is exercised through the operation of some central mechanism (Lack, 1971). Thus, BR control may be considered to be an example of a mechanism of selective attention.

The usual measures of BR control rely on subjective reports of Ss. However, Fox and Check (1966) have demonstrated the objective effect of reduced recognition of test stimuli which are tachistoscopically presented to the eye in the suppression phase of BR. The same technique was used by Collyer and Bevan (1970) to measure the effects of voluntary control of rivalry. Ss were instructed to maintain the dominance of one eye for a complete test session, which resulted in a mean recognition difference of $14 \%$ between the instructed and noninstructed eyes.

There appears to be a large discrepancy between the objective effect of BR dominance control and the subjective measures. Collyer and Bevan (1970) found only a $14 \%$ difference in recognition performance in a forced response task with three alternatives where presumably the maximum possible recognition difference was $67 \%$. Yet even unpracticed Ss, using voluntary control, could vary the BR altemation rate 2.5 times. One of the aims of the present experiment is to clarify the relationship between subjective measures and the objective measure of voluntary control of BR. For instance, are the individual differences in subjective control related to obtained differences in the objective measure? Also, would the increased degree of subjective control resulting from practice be reflected in an increased value of the objective measure?

Recent work (Lack, 1973) would suggest that control of subjectively reported alternation rates should correlate with the objective measure of recognition scores for stimuli presented during rivalry. It was found that Ss could not vary the amplitude of the suppression effect as BR alternation occurred normally. This suggests that the amplitude of suppression is constant and that control of $B R$ is accomplished through varying the duration of dominant and suppression phases. The ability to control the duration of BR phases can be 

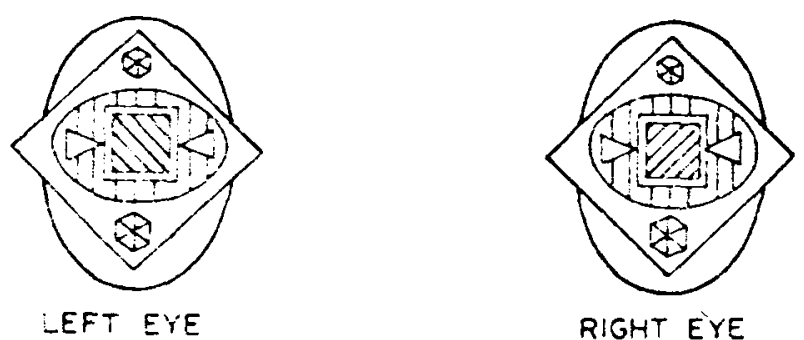

Fig. 1. Left and right fusion and rivalry patterns.

measured when Ss are presented with test stimuli for recognition in the following manner.

An S passively viewing BR is presented with one of two possible auditory signals which instructs him to attend to one eve or the other. Shortly following the onset of this instruction signal, a test stimulus is presented either to the eye containing the instructed (I) rivalry pattern or to the eye containing the noninstructed (NI) pattern. If Ss have no ability to control the durations of phases, then BR will continue according to an involuntary mechanism and the (I) pattern with an equal probability will be in the suppression or the dominant phase at any time following the instruction signal. In this case recognition performance for test stimuli will be equal for the (I) and (NI) eyes and the difference in recognition performance (I-NI) will be zero.

On the other hand, if Ss are able to lengthen the dominant phases and/or to shorten the suppression phases of the instructed pattern after receiving the instruction signal, then the instructed eye will more likely be in the dominant than the suppression phase. In this case (I) recognition will be greater than (NI) and the (I-NI) measure will have a positive value. An important prediction of this experiment is that the objective measure, (I-NI), will be positively correlated with the subjective measure of rivalry control.

The (I-NI) measure in the present experiment would have an advantage over the measure used by Collyer and Bevan (1970) with respect to analyzing the temporal course of selective attention in rivalry. They instructed Ss to make one pattern dominant for an entire session. Yet it is the experience of the author that it would be impossible for unpracticed $S s$ to follow these instructions, since some shifts of attention to the noninstructed pattern will invariably occur. However, Collyer and Bevan's (1970) results provide no information about the temporal course of the rivalry phases.

In the present experiment, the delay between the onset of the attention signal and the presentation of the test stimulus is varied in order to obtain information about the temporal limitations of BR control. For example, if shifting of attention takes some time to occur, then the (I-NI) measure is likely to be less for very short test stimulus delays than for moderate delays. Alternatively, if attention cannot be held indefinitely, then presumably the (I-NI) measure will show some decay after longer test stimulus delays. Also, those individual $S s$ who can produce the highest subjective rates of alternation should be those who can shift attention in the test situation most rapidly and, as a result, show the highest (I-NI) values for the short test stimulus delays. Similarly, those Ss with the lowest slow rates should produce the highest (I-NI) values for the longer stimulus delays. In the present experiment, it will be possible to investigate the normal temporal course of attention in binocular rivalry and to relate selective attention performance after specific test stimulus delays to the individual differences in rivalry rate measures.

\section{METHOD}

\section{Subjects}

Eight males and two females volunteered from the staff and postgraduate students of the Psychology Department of the University of Adelaide to serve as Ss. All had normal or corrected to normal vision. Three (L.L., J.T., and J.R.) had, as a result of at least 10 practice sessions of BR control, developed higher than average subjective measures. Three others (I.P., A.R., and C.C.) had participated in a past experiment involving the observation of rivalry but in which $B R$ control was not practiced. The other Ss (N.K., B.G., E.G., and P.C.) had no previous experience of BR.

\section{Stimuli}

The binocular fusion patterns with included rivalry patterns are shown in Fig. 1. The fusion stimuli for both eyes are identical, each consisting of two concentric squares surrounded by arbitrary and rather complicated geometrical patterns. The purpose of these fusion patterns was to provide a large number of fusion contours to ensure a maximum stability of fusion. When mounted in the previewing field of a tachistoscope, all black lines subtended $10 \mathrm{~min}$ of the visual field. The innermost fusion squares subtended $1 \mathrm{deg} 20 \mathrm{~min}$, and the fusion patterns subtended a horizontal visual angle of $4 \mathrm{deg}$ and a vertical angle of 6 deg.

The rivalry stimuli were similar to those used by Fox and Check (1966), consisting of five parallel lines filling the innermost fusion square at $45 \mathrm{deg}$ to vertical for the right eye and at $135 \mathrm{deg}$ for the left eye. The test stimuli were four capital letters (A, S, T, U) typed on white stimulus cards. The test stimuli subtended 25 min when mounted in the second field of the tachistoscope to coincide with the center of either the left or right rivalry stimuli.

\section{Apparatus}

The basic apparatus consisted of a modified Stereo-king Model $\mathrm{HN}-44$ stereoscope mounted to the viewing hole of a Cambridge two-field tachistoscope. Although accommodation and pupillary changes do not contribute significantly to control of rivalry (Lack, 1971), artificial pupils are useful for minimizing head movement. Therefore, $2.8-\mathrm{mm}$ artificial pupils, adjusted to the interocular distance of any $S$, were mounted in front of the lenses of the stereoscope, and a chinrest was adjusted to provide a stable head position.

The luminance of the black lines of fusion and rivalry contours as measured at the lens with an S.E.I. spot photometer was $0.1 \mathrm{fL}$ and the luminance of the white background was a uniform $1.0 \mathrm{fL}$. The illumination of the test stimulus field provided a luminance of $0.032 \mathrm{fL}$ for the black letter stimuli and $0.4 \mathrm{fL}$ for the white background. 
Other apparatus included a telegraph key, event counter, and cumulative timer to allow the calculation of the degree of subjective control of $\mathrm{BR}$. The continuous depression of the telegraph key by $S$ to indicate the presence of the right eye dominance phase produced one count on the event counter and continuous activation of the cumulative timer. Thus, for a timed period of rivalry, the dominance and suppression time of the right and left eye stimuli were available in addition to the alternation rate of $B R$.

Additional apparatus for the presentation of test stimuli included decade timers and two buzzers. Activation of the first timer produced a 2-sec "ready" interval which was followed by a 0.3 -sec duration "instruction" buzzer, which in turn was followed by the activation of a third decade timer that produced a given delay $(1,3,5$, or $7 \mathrm{sec})$ of test stimulus presentation. A two-position switch enabled $E$ to select for any trial a high-intensity $50-\mathrm{Hz}$ buzzer or low-intensity $100-\mathrm{Hz}$ buzzer.

\section{Procedure}

The general procedure followed on each test trial was as follows. The $E$ inserted a predetermined test stimulus into the test field of the tachistoscope. The E then said "ready" to S and simultaneously pressed the start button. The $S$ was instructed to fixate at the center of the rivalry patterns and to watch the rivalry passively. After $2 \mathrm{sec}$ either the $100-\mathrm{Hz}$ buzzer (the instruction signal for the right eye pattern dominance) or the $50-\mathrm{Hz}$ buzzer (the instruction signal for the left eye pattern dominance) was sounded. The Ss were to bring the instructed rivalry pattern into dominance as quickly as possible (if it was not already dominant) and to maintain that dominance as long as possible. The Ss were told not to blink or to move their fixation from the center of the rivalry patterns, but to use attention or concentration only as the means for following the instructions. The test stimulus followed the instruction signal by a $1-, 3-, 5-$, or $7-\sec$ delay. Immediately following the test stimulus presentation, the $S$ responded with one of the four letter stimuli as quickly as possible. Then $S$ was to rate his/her confidence in the correctness of the response on a 4-point rating scale in which " 4 " represented very high confidence that the response was correct and " 1 " represented no confidence that the response was correct. The S's response was followed by a rest interval of about $15 \mathrm{sec}$ in which the $E$ inserted the next test stimulus and set the next instruction signal and interval of test stimulus delay.

Pretest and posttest sessions yielded two measures of subjective BR control. The previously mentioned measure of control of alternation rate was derived from four $60-\mathrm{sec}$ trials of which two slow rate trials and two rapid rate trials were presented in balanced order. The mean slow rate and mean rapid rate for an $S$ determined the measure of rate control based on the following formula: percentage rate control = (rapid rate slow rate)(100)/(rapid rate + slow rate). The second subjective control measure was based on four 60 -sec trials of which two instructed right-eye-dominant and two instructed left-eye-dominant trials were presented in balanced order. From the accumulated time in which the instructed eye pattern was, in fact, dominant (dominant time) and from the time in which it was suppressed (nondominant time), a measure of rivalry dominance control, similar to that used by Washburn and Gillette (1933), could be calculated with the following formula: percentage dominance control $=($ dominant time - nondominant time $)(100) /$ total time.

Following the pretest session, Ss were tested to establish tachistoscopic exposure durations for each eye in the monocular viewing condition using a descending staircase method with knowledge of results that would give approximately $50 \%$ correct recognition performance. In meeting this criterion no exposure duration exceeded $70 \mathrm{msec}$. Ss were then given 20 presentations of the two instruction signals presented in random order and were required to name each stimulus as quickly as possible by
Table 1

Mean Percentage BR Rate Control, Percentage Recognition Scores from Both Eyes Combined Under the Instructed (I) and Noninstructed (NI) Conditions, and Probability of the Difference Under $\mathrm{H}_{\mathrm{o}}$

\begin{tabular}{lccccl}
\hline Subject & $\begin{array}{c}\text { BR } \\
\text { Control }\end{array}$ & I & NI & I - NI & $\begin{array}{c}\text { p } \\
\text { Level }\end{array}$ \\
\hline L.L. & 76.1 & 63.0 & 45.8 & 17.2 & .013 \\
J.T. & 91.4 & 56.8 & 31.3 & 25.5 & .0001 \\
N.K. & 45.4 & 54.2 & 38.5 & 15.7 & .015 \\
B.G. & 58.4 & 72.4 & 52.6 & 19.8 & .01 \\
E.G. & 34.7 & 51.1 & 41.7 & 9.4 & .10 \\
J.R. & 47.2 & 64.6 & 45.8 & 18.8 & .01 \\
I.P. & 31.9 & 57.3 & 43.2 & 14.1 & .05 \\
A.R. & 49.1 & 61.5 & 54.2 & 7.3 & .192 \\
C.C. & 46.0 & 54.8 & 41.7 & 13.1 & .05 \\
P.C. & 57.5 & 53.2 & 35.9 & 17.3 & .01 \\
Mean & 53.8 & 58.9 & 43.1 & 15.8 & .0005 \\
\hline
\end{tabular}

saying "right" or "left." Then Ss were given a further 20 trials in which they simulated the experimental conditions by attempting to control the direction of the dominance phase of rivalry according to the randomly presented instruction signal. By the end of these training trials, all Ss were confident in knowing the correct relationship between each auditory instruction signal and the appropriate eye pattern to be made dominant.

The experiment proper consisted of a total of 384 trials conducted in six 64-trial sessions of about 20 min duration each. Each session of 64 trials consisted of all possible conditions of test stimulus presentation resulting from the multiplication of the two instruction signals by the two eyes to which test stimuli may be presented by the four possible delays of test stimuli by the four possible letter stimuli. Each of the six sessions had the 64 possible trials in different random orders based on random permutation tables from Moses and Oakford (1963). Ss were informed at the beginning of the experiment of all the conditions of test stimulus presentation and of the fact that they were equally probable and in random order. Throughout the experiment Ss were given no knowledge of results.

\section{RESULTS}

\section{Objective Effects of Rivalry Control}

Table 1 shows the percent recognition scores for Ss when test stimuli were presented to the instructed and noninstructed eyes, the (I-NI) measure, and the probability level under the null hypothesis, $\mathrm{H}_{0}$. Using a Z-score transformation for large samples in the sign test, it was found that eight Ss obtained less than a 0.05 probability value and four of these Ss obtained less than a 0.01 value for the (I-NI) measure. The mean recognition difference between test stimuli presented to the instructed and noninstructed eyes was $15.8 \%$, which reached a high significance level $(t=8.88, d f=9$. $\mathrm{p}<.0005)$.

\section{Effect of Test Stimulus Delay}

The mean percentage recognition scores for the combined instructed and noninstructed conditions, $(\mathrm{I}+\mathrm{NI}) / 2$, and for the (I-NI) measure of control are 
Table 2

Mean Combined $[(\mathbf{I}+\mathrm{NI}) / 2]$ and Mean Difference $(\mathrm{I}-\mathrm{NI})$ Percentage Recognition Scores of Instructed (I) and Noninstructed (NI) Conditions With Associated Significance Levels of the Difference Between I and NI for Each Test Stimulus Delay

\begin{tabular}{|c|c|c|c|c|}
\hline & \multicolumn{4}{|c|}{ Test Stimulus Delay (Seconds) } \\
\hline & 1 & 3 & 5 & 7 \\
\hline$(\mathrm{I}+\mathrm{NI}) / 2$ & 53.2 & 51.8 & 49.8 & 49.1 \\
\hline $\mathrm{I}-\mathrm{NI}$ & $15.0^{* *}$ & $19.0^{* *}$ & $17.3^{* *}$ & $11.9^{*}$ \\
\hline
\end{tabular}

shown in Table 2. The differences between I and NI are significant to the $\mathrm{p}=.01$ level for all stimulus delays. Although the mean recognition performance appears to decline linearly with length of stimulus delay, the difference between the $1-\mathrm{sec}$ and $7-\mathrm{sec}$ delay does not reach a significant level $(\mathrm{t}=1.4, \mathrm{df}=9, \mathrm{p}>.10)$. On the other hand, there is a significant difference $(t=2.07, \mathrm{df}$ $=9, \mathrm{p}<.05$ ) between the $19.0 \%(\mathrm{I}-\mathrm{NI})$ value of the $3-\mathrm{sec}$ delay and $11.9 \%$ value of the 7 -sec delay.

These results are consistent with the subjective measures of rivalry control. The initial mean rapid rate was 37.5 alternations/min and mean slow rate was 11.0 alternations $/ \mathrm{min}$. The mean phase durations for these rates are, respectively, $1.60 \mathrm{sec}$ and $5.45 \mathrm{sec}$. Most Ss in the present experiment take longer than $1 \mathrm{sec}$ to shift attention voluntarily in rivalry when attempting to shift as rapidly as possible, and most Ss could not maintain a given phase of rivalry for as long as $7 \mathrm{sec}$ when attempting to retard the alternations as much as possible.

\section{Correlation of Subjective and Objective Measures}

The subjective measures of control were found to be highly reliable. The pretest and posttest correlation of rate control was significant at a high level $(r=+.931$, df $=8, \mathrm{p}<.005)$ and the mean rate control was correlated with the mean dominance control at a high level of significance $(\mathrm{r}=+.932, \mathrm{df}=8, \mathrm{p}<.005)$. The objective measure of rivalry control (I-NI) is also fairly reliable. The Pearson correlation of the (I-NI) measure between the first and second halves of the experiment was significant $(\mathrm{r}=+.790, \mathrm{df}=8, \mathrm{p}<.005)$. Both the ability to control the subjective aspect of binocular rivalry and the ability to produce a difference in recognition performance between the instructed and noninstructed eyes is fairly consistent within Ss.

Comparing subjective and objective measures. the Pearson correlation of the combined pre- and posttest session mean rate control and the (I-NI) measure was significant $(\mathrm{r}=+.742$, $\mathrm{df}=8, \mathrm{p}<.01)$ as was the correlation of mean dominance control and the (I-NI) measure $(\mathrm{r}=+.632, \mathrm{df}=8, \mathrm{p}<.025)$. The best fit regression line for predicting (I-NI) values from rate control measures had a slope, $b=+0.224$, and intersected the $0 \%$ control value at a (I-NI) value of $4 \%$, which does not differ greatly from the predicted (I-NI) value of $0 \%$. In addition, the best fit line intersected the $100 \%$ control value at a (I-NI) value of $26 \%$, considerably less than the maximum value of $75 \%$, which suggests an upper limit to the difference that can be obtained in the objective recognition measure even with maximum control of subjective rivalry.

The more specific predictions relating individual slow and rapid rates to the (I-NI) measures for specific delays of test stimuli were tested. The Pearson correlation of rapid rate with the (I-NI) measure for the $1-\mathrm{sec}$ delay reached a low level of significance $(r=+0.455, \mathrm{df}=8$, $p<.10$ ). Although the correlation of slow rate with the (I-NI) measure at the 7-sec delay was not significant ( $r=$ -.260 . df $=8, p>.10$ ), the correlation at the $5-\mathrm{sec}$ delay was significant $(r=-.623, d f=8, p<.05)$. This is probably due to restriction of range for the (I-NI) values at the $7-\mathrm{sec}$ delay. Since the mean slow rate phase duration was $5.45 \mathrm{sec}$ and only three Ss had slow rate phase durations longer than $7 \mathrm{sec}$, fewer Ss would have significant (I-NI) values at the $7-\mathrm{sec}$ delay. Thus, the $5-\sec$ delay would differentiate more effectively than the $7 \cdot \sec$ delay between those Ss with slower and those with more rapid slow rates. In summary, those Ss with greater rapid rates are generally better able to direct the phases of rivalry in the recognition task within $1 \mathrm{sec}$ of receiving the directional instructions and those $\mathrm{Ss}$ with the slowest slow rates can best maintain the instructed rivalry phases as long as $5 \mathrm{sec}$ but not necessarily as long as $7 \mathrm{sec}$ after the instruction signal.

\section{The Effect of Practice}

In the present experiment, the effect of practice of rivalry control can be examined in two ways. First, it may be recalled that three Ss (L.L., J.T., and J.R.) were well practiced in the control of rivalry. The mean pretest rate control for this subgroup was $71.5 \%$ and significantly greater $(t=3.37, \mathrm{df}=8, \mathrm{p}<.005)$ than the pretest rate control of the seven unpracticed Ss. A comparison of these two subgroups showed a (I-NI) measure for the practiced Ss for $20.5 \%$, which was significantly greater $(t=2.06$, df $=8, p<.05)$ than the mean of $13.6 \%$ for the unpracticed Ss. It is interesting that the same measure applied to the results of Collyer and Bevan (1970) with a three-alternative response task is $14.0 \%$. If the percentage correct values are converted into standardized signal strength $\left(d^{\prime}\right)$ values using Table II of the appendices of Swets (1964), the unpracticed $S s$ in the present experiment would have a mean $d^{\prime}$ difference of 0.42 which is very similar to the $d^{\prime}$ value of 0.45 for the unpracticed $S s$ of Collyer and Bevan (1970). The seven Ss in the present experiment would seem to be fairly representative of unpracticed Ss in general. Practiced Ss, on the other hand, showed a d' difference between attended and nonattended eyes of 0.63 .

Given the above mean difference in BR control between practiced and unpracticed Ss, the question may 
be raised as to what extent the inclusion of practiced Ss contributed to the correlation between rate control and the (I-NI) measure. If these three Ss are excluded, the correlation between rate control and the objective measure is still significant $(\mathrm{r}=+.682, \mathrm{df}=5, \mathrm{p}<.05)$. The (I-NI) measure is a reliable, objective measure of the degree of rivalry control in both unpracticed Ss and in Ss whose control has been increased with practice.

One may also examine the effect of practice resulting from the experimental trials themselves on the subjective and objective BR control measures. Ss were instructed to shift the dominance phase and maintain it on the instructed pattern for each of 384 trials. Assuming that the duration of the voluntary control averaged $3 \mathrm{sec}$ per trial, Ss obtained a total of $20 \mathrm{~min}$ of control practice throughout the experiment. According to earlier results of the present author (1970), the spaced practice without knowledge of results should produce an increase of the subjective measure of control. In fact, an increase of $10.4 \%(\mathrm{t}=2.53, \mathrm{df}=9, \mathrm{p}<.025)$ was found in the rate control measure between pre- and posttest sessions, and an increase of $5.3 \%(\mathrm{t}=4.4, \mathrm{df}=9, \mathrm{p}<.005)$ was found in the (I-NI) measure between the first and second halves of the experiment. In addition, the increases of rate control were significantly correlated $(\mathrm{r}=+0.647 \mathrm{df}$ $=8, \mathrm{p}<.025)$ with the increases of the (I-NI) measure. Furthermore, these increases were exclusively related to each other and were not correlated with total recognition performance, with the mean (I-NI) measure, or with the mean subjective control measure. The general increases of rate control and objective measure result mainly from those Ss who show increases of both measures as a result of the practice of the control required in the experiment.

\section{Analysis of Confidence Ratings}

Forced-choice recognition tasks have rarely used confidence rating scales, since they are discrimination rather than simple detection tasks. However, information is available about the confidence of forced-choice judgments in discrimination tasks (Egan \& Clarke, 1966). Pollack and Decker (1958) have shown how this information can be measured using a confidence rating scale. Obtaining the confidence judgments of $\mathrm{Ss}^{\prime}$ responses does not interfere with recognition performance, and it provides useful information about the receiver's operating characteristics (ROC) (Pollack \& Decker, 1958). The use of the confidence rating scale in the present experiment provides two additional ways of comparing performance in the instructed and noninstructed conditions besides that of percentage correct scores: (1) the comparison of confidence levels by analyzing the use of confidence ratings, and (2) the visual comparison of relative signal strengths of the two conditions using ROC curves.

By calculating the probabilities of a correct response for specific confidence ratings for both instructed and

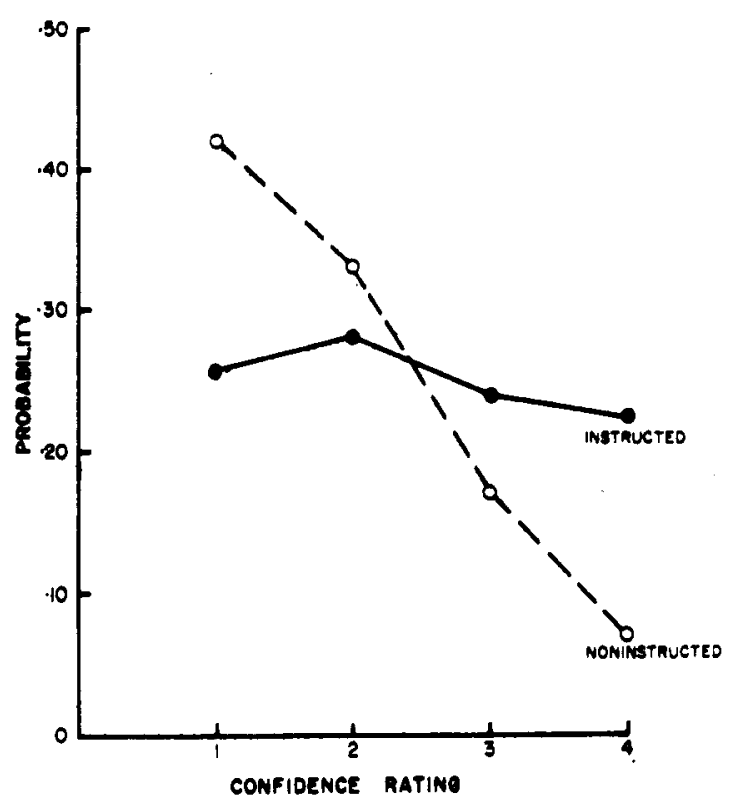

Fig. 2. Probability of each of the four confidence ratings.

noninstructed eyes, the confidence criteria of the two conditions may be directly compared. If a more confident (less conservative) criterion is used when test stimuli are presented to the instructed eye than when presented to the noninstructed eye, the result would be a lower probability of a correct response for the instructed eye with the use of a specific rating value. For example, if rating " 2 " has a lower probability correct value in the instructed condition than in the noninstructed, it would indicate a greater confidence in the instructed condition regardless of differences of signal strength. On the other hand, if Ss have the same confidence criteria for the same rating values under both conditions, the probabilities of a correct response will be equal. Then if signal strength is greater in the instructed condition, Ss will, of course, use more " $3 \mathrm{~s}$ " and " $4 \mathrm{~s}$," resulting in a greater mean confidence rating than in the noninstructed condition.

In fact, the mean confidence rating in the instructed condition is 2.44 and is significantly greater $(t=3.05$, df $=9, \mathrm{p}<.01)$ than the noninstructed mean confidence rating of 1.90 . Figure 2 shows the probability distribution of responses to the four rating categories for both the instructed and noninstructed conditions. It is clear that Ss make a greater use of the high confidence ratings (" 3 " and "4") in the instructed condition and a greater use of the low confidence ratings (" 1 " and " 2 ") in the noninstructed condition.

The question of whether Ss maintain the same confidence criteria between conditions may be answered directly by comparing the probabilities of a correct response. Figure 3 shows the probabilities of a correct response for the four ratings of each condition. The fact that the probabilities increase monotonically from Confidence Rating "1" to Rating "4" suggests that Ss 


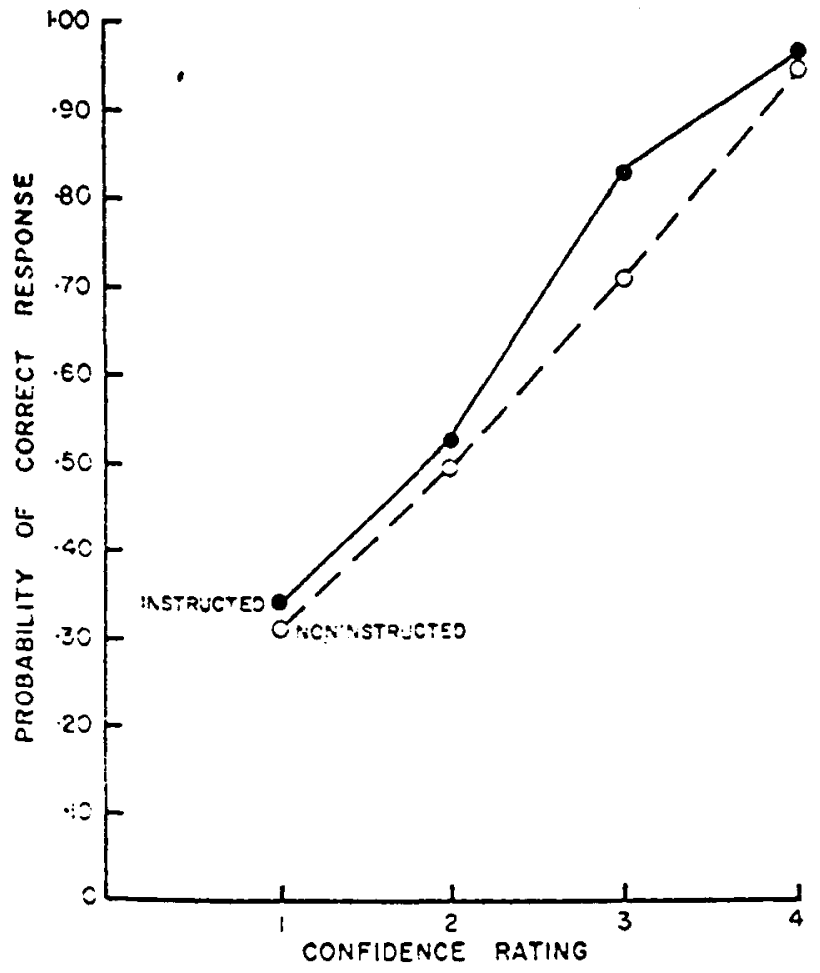

Fig. 3. Probability of a correct response with each of the four confidence ratings.

were correctly following instructions in the assignment of confidence ratings.

The probabilities of a correct response are similar for all conditions. The largest difference between the conditions is with the use of Confidence Rating " 3 ." However, this difference does not reach even a low significance level $(t=1.15, d f=9, p>.10)$. It seems, then. that $S$ s use the same criterion of confidence for a given rating value in both the instructed and noninstructed conditions.

The ROC curves for the instructed and noninstructed conditions are shown in Fig. 4. The ordinate is the linear cumulative probability of a correct acceptance or "hit" (Ss judged probability of a correct response when, in fact, the response was correct). The abscissa is the linear cumulative probability of a "false alarm" (Ss judged probability of a correct response when, in fact, the response was not correct). The greater deviation of the instructed condition curve from the 45-deg diagonal indicates a greater $d^{\prime}$ value $(1.09)$ than for that of the noninstructed condition $\left(d^{\prime}=0.60\right)$.

The present results are similar to those of selective attention in dichotic listening. Broadbent and Gregory (1963) found that signal strength increased from $d^{\prime}=$ 2.90 to $\mathrm{d}^{\prime}=5.05$, but that confidence criteria (be ta) did not change when Ss shifted attention to the ear in which the signal occurred. Treisman and Geffen (1967) found a d' difference of 2.4 for target stimuli but no significant difference in beta between the shadowed and nonattended ears in dichotic listening. In a dichotic listening task without shadowing. Moray and O'Brien (1967) found a d' difference of 2.28 but no significant difference in beta between the attended and nonattended ears. A difference in $\mathrm{d}^{\prime}$ value with no change in confidence criteria was also the general finding in the present experiment.

On the other hand, there is a difference between the effects of the control of rivalry and selective attention in dichotic listening with respect to the magnitude of the $\mathrm{d}^{\prime}$ difference. The smallest mean difference in $\mathrm{d}^{\prime}$ in the selective listening experiments was 2.15 , while the mean $\mathrm{d}^{\prime}$ difference from selective attention in the present experiment was only 0.49 .

The comparatively small d' difference from rivalry control appears to result from a limit on the magnitude of the suppression effect of rivalry rather than from a limit to the degree of control. S J.T. with a considerable degree of BR control produced the largest (I-NI) measure equivalent to a $\mathrm{d}^{\prime}$ difference of 0.80 . The predicted (I-NI) measure of $26 \%$ for a projected $100 \%$ $\mathrm{BR}$ control would be equivalent to a $\mathrm{d}^{\prime}$ difference of 0.80 . In addition, the $d^{\prime}$ difference arising between dominant and suppression phases in passive rivalry seems to be limited. When Fox and Check (1966) ensured that target stimuli were presented only during completely dominant or completely suppressed phases of rivalry, they found a maximum effect equivalent to a $\mathrm{d}^{\prime}$ difference of 0.90 . More recently, Lack (1973) found a mean $d^{\prime}$ difference between the dichotomous dominant and suppression phases of passive rivalry of only 0.66 .

The limit on the magnitude of the (I-NI) measure may merely be a result of the test stimulus method in the present experiment. Wales and Fox (1970) suggested

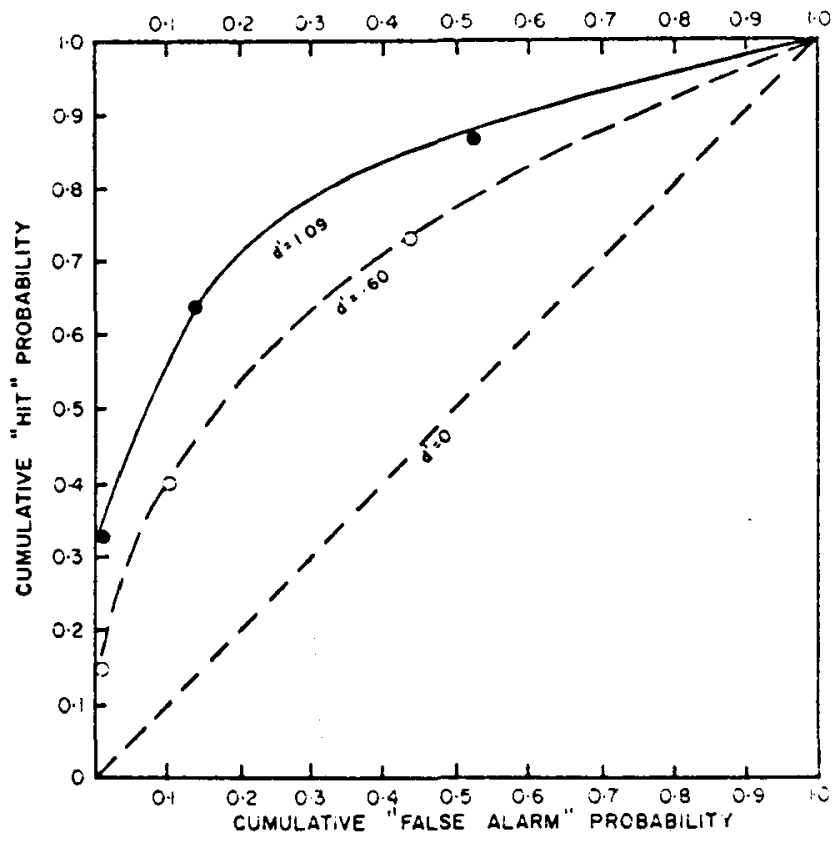

Fig. 4. ROC curves of the instructed (solid lines) and noninstructed (broken lines) conditions. 
that rivalry suppression produces a constant decrease of sensitivity of about $0.5 \mathrm{log}$ units compared with the dominant phase condition. Since test stimuli are presented tachistoscopically and produce a change in stimulus conditions from that of the unchanging rivalry stimuli, the test stimuli are likely to penetrate the suppression phase inhibition with only somewhat at tenuated intensity or information value. On the other hand, the test stimuli in the dichotic listening tasks were embedded in a series of continuously new stimuli. This difference in test stimulus methods may account for the control of rivalry resulting in a smaller $\mathrm{d}^{\prime}$ difference than selective attention in dichotic listening.

The relationship between the objective and subjective measures of BR control has been clarified. The (I-NI) measure is positively correlated with the subjective measures of control of rivalry rate and ocular dominance. Although all measures of BR control are significantly but not dramatically large for unpracticed Ss, they are increased with the practice of both rate control and the control required in the objective task.

Specific predictions relating rate control and performance at different delays of test stimuli were also verified. Ss with the greatest control in producing a rapid rate of rivalry generally showed the largest objective measures for the shortest test stimulus delay. On the other hand, Ss with greatest control of slow rate generally showed greater objective measures for the longer stimulus delays. Therefore, the objective measure, (I-NI), in the present experiment is a valid indicator of the general ability to control the alternations or phases of rivalry. In addition, the analysis of performance at various intervals following the attention instructions has shown relationships between the objective measure and specific abilities for producing a rapid or slow rivalry rate.

In general, the temporal course of the control of rivalry phases shows an increase in control from $1 \mathrm{sec}$ to a maximum (I-NI) value $3 \mathrm{sec}$ after the instruction signal. There is a slight decline in the obiective measure from $3 \mathrm{sec}$ to $5 \mathrm{sec}$. But the decline does not become significant until $7 \mathrm{sec}$ following the instruction signal. These results suggest some minimum time to shift attention in rivalry. However, since the objective measure is significant for the 1 -sec delay, at least some Ss can shift rivalry phases within $1 \mathrm{sec}$ of the attention instructions.

Broadbent (1958) suggested that the minimum shifting time in a dichotic listening task is not negligible compared with recognition time and may be in the order of $1 / 6 \mathrm{sec}$. His estimate was complicated by the consideration of recognition times in a task requiring short-term memory storage. Since in the present experiment recognition and short-term memory storage times are not involved, the minimum shifting time can be directly determined by the introduction of shorter delays of test stimuli until the (I-NI) measure reduces to zero or at least fails to remain significant. In any case, from the present experiment it can be concluded that if there is a minimum shifting time in the control of binocular rivalry, it is less than $1 \mathrm{sec}$.

Pillsbury (1908) suggested that attention may dwell exclusively on one stimulus for a maximum of from 3 to $24 \mathrm{sec}$ but that the normal "span of attention" is about 5 to $8 \mathrm{sec}$. In the present experiment, the "span of attention" may be calculated as the reciprocal of the slow rate or may be estimated from the decline of the objective measure with greater test stimulus delays. Both the mean phase duration of $5.45 \mathrm{sec}$ under slow rate instructions and the fact that the (I-NI) measure shows a significant decline by the 7 -sec delay suggest that the "span of attention" for some Ss is between 5 and $7 \mathrm{sec}$. However, this maximum attention time in binocular rivalry shows large individual differences and is also very much affected by practice.

\section{REFERENCES}

Broadbent, D. E. Perception and communication. London: Pergamon Press, 1958.

Broadbent, D. E., \& Gregory, M. Division of attention and the decision theory of signal detection. Proceedings of the Royal Society of London, Series B, 1963, 158, 222-231.

Collyer, S. C., \& Bevan, W. Objective measurement of dominance control in binocular rivalry. Perception \& Psychophysics, $1970,8,437-439$.

Egan, J. P., \& Clarke, F. R. Psychophysics and signal detection. In J. B. Sidowski (Ed.), Experimental methods and instrumentation in psychology. New York: McGraw-Hill, 1966. Pp. 211-246.

Fox, R., \& Check, R. Forced-choice form recognition during binocular rivalry. Psychonomic Science, 1966, 6, 471472.

Helmholtz, H. von. Popular lectures on scientific subjects. (Trans. E. Atkinson) London: Longmans, Green, 1873.

Helmholtz, H. von. Treatise on physiological optics. (Trans. J. P. Southall) Vol. III. New York: Dover, 1925.

James, W. The principles of psychology. London: MacMillan, 1891. (Republished: New York, Dover, 1962.)

Lack, L. C. The effect of practice on binocular rivalry control. Perception \& Psychophysics, 1969, 6, 397-400.

Lack, L. C. Effects of knowledge of results and spacing of practice trials in training of control of binocular rivalry. Perceptual \& Motor Skills, 1970, 31, 827-830.

Lack, L. C. The role of accommodation in the control of binocular rivalry. Perception \& Psychophysics, 1971, 10, 3842.

Lack, L. C. Amplitude of visual suppression during the control of binocular rivalry. Perception \& Psychophysics, 1973, in press.

McDougall, W. The physiological factors of the attention-process (III). Mind, 1903, 12, 473-488.

Meredith, G. M., \& Meredith, C. G. W. Effect of instructional conditions on rate of binocular rivalry. Perceptual \& Motor Skills, 1962, 15, 655-664.

Moray, N. Attention: Selective processes in vision and hearing. London: Hutchinson Educational, 1969.

Moray, N., \& O'Brien, T. Signal-detection theory applied to selective listening. Journal of the Acoustical Society of America, 1967, 42, 765-772. 
Moses, L. E., \& Oakford, R. V. Tables of random permutations. Stanford, Calif: Stanford University Press, 1963.

Pillsbury, W. B. Attention. New York: MacMillan, 1908.

Pollack, I., \& Decker, L. R. Confidence ratings, message reception, and the receiver operating characteristic. Journal of the Acoustical Society of America, 1958, 30, 286-292.

Swets, J. A. (Ed.) Signal detection and recognition by human observers. New York: Wiley, 1964.

Swets, J. A., \& Kristofferson, A. B. Attention. Annual Review of Psychology, 1970, 21, 339-366.

Treisman, A. M. Strategies and models of selective attention. Psychological Review, 1969, 76, 282-299.

Treisman, A. M., \& Geffen, G. Selective attention: Perception or response? Quarterly Journal of Experimental Psychology, $1967,19,1-17$.
Wales, R., \& Fox, R. Increment detection thresholds during binocular rivalry suppression. Perception \& Psychophysics, $1970,8,90-94$.

Washburn, M. F., \& Gillette, A. Studies from the psychological laboratory of Vassar College: LXII. Motor factors in voluntary control of cube perspective fluctuations and retinal rivalry fluctuations. American Journal of Psychology, 1933, 45, 315-319.

(Received for publication June 29, 1973; accepted September 20,1973.) 